\title{
A general approach for encapsulation of biomolecules using MOF particles
}

Da Zou, ${ }^{a}$ Lei Yu, ${ }^{a}$ Qi Sun, ${ }^{a}$ Yue Hui, ${ }^{a}$ Tengjisi, ${ }^{a}$ Yun Liu,,${ }^{a}$ Guangze Yang, ${ }^{a}$ David Wibowo, ${ }^{\text {* }}$ Chun-Xia Zhao ${ }^{\mathrm{a}^{*}}$

a Australian Institute for Bioengineering and Nanotechnology, The University of Queensland, St Lucia QLD 4116, Australia

${ }^{\mathrm{b}}$ Centre for Cell Factories and Biopolymers, Griffith Institute for Drug Discovery, Griffith University, Nathan QLD 4111, Australia

*Corresponding authors: D.W. (d.wibowo@griffith.edu.au) and C.-X.Z. (z.chunxia@uq.edu.au)

\section{Abstract}

Encapsulation of biomoleucles in metal organic frameworks (MOFs) has recently attracted significant interest because of the benign process including room temperature, neutral $\mathrm{pH}$ and without the requirement of any other chemical reagents. Also, these biomolecule incorporated MOFs (biomolecules@MOFs) have demonstrated their potential in biomolecule protection and controlled release. This work aims to develop a general strategy to make biomolecules@MOFs via a biomimetic mineralization process. A library of biomolecules (peptides and proteins) with different charges were systematically studied to fundamentally understand the role of biomolecules and their proprieties in biomolecule-mediated MOF biomineralization. Biomolecule charge, amino acid sequence and stirring speed have been demonstrated to play important roles in controlling biomineralization reaction rate, particle shape and morphology.

\section{Short statistical summary:}

Total number of words: 3852

Tables: 1

Figures: 7 


\section{Introduction}

Metal organic frameworks (MOFs) are a class of porous materials made by linking inorganic and organic units with strong bonds ${ }^{1}$. Because of their distinctive topologies and structure, MOFs have shown promise in many applications such as drug encapsulation and delivery ${ }^{2}$, catalysis $^{3}$, separation ${ }^{4}$ and chemical sensing ${ }^{5}$. Generally, MOFs are synthesized via traditional crystal engineering routes. Only recently, considerable efforts have been dedicated to fabricate MOFs using biomimetic mineralization approaches, where biomolecules are used as crystallization and directing agents to engineer a range of MOFs ${ }^{6-8}$. This method has been used to synthesize MOF-based particles composed of biomolecules including enzymes ${ }^{9}$, proteins ${ }^{10}$, peptides ${ }^{11}$, cells ${ }^{12}$, DNA ${ }^{13}$ and viruses ${ }^{14}$. These kinds of biomolecules@ MOFs have demonstrated great potential for encapsulating and protecting biomolecules during long-term storage 1516 .

Zeolite imidazolate frameworks (ZIFs) represent a class of MOFs for various potential applications due to their excellent properties ${ }^{17}$. Among the previously reported MOF candidates for biomimetic mineralization, ZIF, a material with network composed of tetrahedral $\mathrm{Zn}^{2+}$ nodes linked together via 2-methylimidazole bridging units ${ }^{18}$ has been widely studied because of its stability in solution and mild synthetic conditions ${ }^{10,19,20}$ It has been recognized that the presence of biomolecules may enhance or impede ZIFs formation depending on the properties of the biomolecules ${ }^{21}$. In order to develop a general strategy to make biomolecules@ZIFs, it is of great interest to understand the role of biomolecules and their properties in biomolecule-mediated ZIF biomineralization.

Here we investigate the effect of peptide or protein sequence on biomimetic mineralization of ZIFs, and propose a general approach to make peptide@ZIFs via a biomimetic mineralization process. The reaction rate of peptide@ZIFs formation was investigated and compared using different types of peptides with different isoelectric point $(\mathrm{pI})$. The effect of peptide sequence, peptide charge, and mixing on ZIF particle size, charge and particle morphology was studied using dynamic light scattering (DLS) and Transmission Electron Microscopy (TEM). The biomolecule@ZIF particles were also characterized using X-ray diffraction (XRD) and Fourier transform infrared spectroscopy (FTIR).

\section{Experimental section Materials}

2-methylimidazole, zinc acetate dihydrate, bovine serum albumin (BSA), lysozyme and fluorescein isothiocyanate (FITC) dye were obtained from Sigma Aldrich (Australia). The peptides, $\mathrm{SurSi}^{22}$, AM1 ${ }^{23}$, M6A peptide and pexiganan, were custom synthesized by GenScript Corporation (Piscataway, NJ, USA), while Lac21 ${ }^{24}$, Lac21K and Lac21E were custom synthesized by Auspep Pty Ltd (Parkville, Australia). The purity of each peptide was $>95 \%$ by reversed-phase high-performance liquid chromatography (RP-HPLC). DAMP4 protein was produced and purified from recombinant Escherichia coli BL21(DE3) as described previously 
25. PS-pexiganan-HH peptide was produced in recombinant E. coli BL21(DE3) as a fusion protein by linking at the $\mathrm{N}$ terminus of DAMP4 ${ }^{26,27}$. Cleavage, isolation and purification of PS-pexiganan-HH peptide from the fusion protein used the methods established in our laboratory ${ }^{26}$. The recombinant protein/peptide profiles were confirmed by sodium dodecyl sulfate-polyacrylamide gel electrophoresis (SDS-PAGE) and the concentrations were measured using RP-HPLC ${ }^{26,28}$. All the recombinant protein and peptide were lyophilized prior to use. Water (resistivity $>18.2 \mathrm{M} \Omega \cdot \mathrm{cm}$ ) was obtained from a Milli-Q system (Millipore, Australia) equipped with a $0.22 \mu \mathrm{m}$ filter.

\section{ZIFs Synthesis}

Various amount of SurSi peptide was dissolved in water to make SurSi solutions of $0.2 \mathrm{~mL}$ with concentrations of $10,20,50,100,500$ and $1000 \mu \mathrm{M}$. Then $0.2 \mathrm{~mL}$ SurSi was added to 0.2 $\mathrm{mL}$ of $240 \mathrm{mM}$ 2-methylimidazole and then vortex for 10 seconds. Next $0.2 \mathrm{~mL}, 60 \mathrm{mM}$ zinc acetate was added to the solution and stirred with different speeds for 12 hours. Finally, the complex was washed using $1.5 \mathrm{~mL}$ water twice and $1.5 \mathrm{~mL}$ ethanol, and then resuspended in $0.5 \mathrm{~mL}$ water.

To obtain other biomolecules@ZIFs, $0.2 \mathrm{~mL}$ of $100 \mathrm{mM}$ pexiganan, lysozyme, Lac21K, PSpexiganan-HH, AM1, Lac21, DAMP4, BSA, Lac21E and M6A were used. $0.2 \mathrm{~mL}$ of these biomolecule solutions were added to $0.2 \mathrm{~mL}$ of $240 \mathrm{mM}$ 2-methylimidazole and then vortex for 10 seconds. Next, $0.2 \mathrm{~mL}$ of $60 \mathrm{mM}$ zinc acetate was added to the solution and stirred for 12 hours. Finally, the complex was washed using $1.5 \mathrm{~mL}$ water twice and $1.5 \mathrm{~mL}$ ethanol, and then resuspended in $0.5 \mathrm{~mL}$ water.

\section{FITC-tagged peptide}

FITC was dissolved in water and mixed with SurSi and reacted for 12 hours in darkness at 4 ${ }^{\circ} \mathrm{C}$ under gentle stirring. The solution was dialyzed against water using a dialysis membrane having a cut-off molecular weight of $3 \mathrm{kDa}$ (Thermo Fisher Scientific, Australia) for 40 hours at $4{ }^{\circ} \mathrm{C}$ to remove the remaining free dye.

\section{Materials characterization}

Transmission electron microscopy (TEM) images were taken using a JEOL 1010 (JEOL, Tokyo, Japan) operated at $100 \mathrm{kV}$. To prepare samples, $2 \mu \mathrm{L}$ of the ZIFs suspensions were placed on Formvar-coated copper grids (ProSciTech, Townsville, Australia) and dried in air. Scanning electron microscope (SEM) images were taken using a JEOL 6610 (JEOL Tokyo, Japan) with an operating voltage of $10 \mathrm{kV}$. Confocal laser scanning microscopy (CLSM) images were recorded on a Zeiss LSM 710 confocal laser scanning microscope (Jena, Germany). The FITC-tagged biomolecules were excited at $488 \mathrm{~nm}$, and the fluorescence signal was collected in a spectral window from 495 to $545 \mathrm{~nm}$. X-ray diffraction (XRD) was performed on a Rigaku R-Axis Spider diffractometer with an image plate detector using $\mathrm{Cu} \mathrm{K} \alpha$ radiation $(\lambda=1.54 \AA)$ and a graphite monochromator. XRD samples were prepared by mixing a small amount of dried framework with a droplet of mineral oil followed by mounting on a 
cryoloop. Fourier transform infrared (FTIR) Spectroscopy experiments were performed using a Fourier transform infrared instrument (iSTM50 ATR-FTIR, Nicolet) (Thermo Fisher Scientific, Scoresby, Australia). To prepare FTIR samples, the washed ZIF suspensions were centrifuged $(10,000 \times g, 10 \mathrm{~min})$ and pellets were air-dried at $60{ }^{\circ} \mathrm{C}$ in oven and characterized using the diamond attenuated-total-reflection (ATR) module of the FTIR. Hydrodynamic sizes and $\zeta$ potentials of the ZIFs particles were determined using a Malvern Zetasizer Nano ZS (Malvern Instruments, Malvern, UK) at a scattering angle of $173^{\circ}$ and a temperature of $25^{\circ} \mathrm{C}$. Ultraviolet-visible (UV-VIS) spectra were recorded on a on a Shimadzu UV-2450 spectrometer (Shimadzu, Japan). To obtain a sample, $200 \mu \mathrm{L}$ of ZIFs solution was placed into a quartz cuvette.

\section{Results and Discussion}

ZIFs represent a subclass of MOFs comprised of imidazolate linkers and metal ions, with structures similar to conventional aluminosilicate zeolites ${ }^{18}$. The biomolecule@ZIF materials show promise in biomolecule capture, encapsulation, protection, controlled release and so on 12. In a typical biomimetic mineralization experiment, an aqueous solution containing biomolecules (including proteins, nucleic acids, polysaccharides and their derivatives) together with 2-methylimidazole (HmIm) is mixed with an aqueous solution of zinc acetate at room temperature. Then transparent solution turns opaque indicating the formation of biomolecules@ ZIFs.

Many studies claimed that only biomolecules with low isoelectric point (pI) or with negative charge can make biomolecules@ZIFs ${ }^{11,21,29-31}$. To study the effect of peptides or proteins with different $\mathrm{pI}$ and charge on ZIF formation, we selected 11 biomolecules with pI from 3.6 to 12.35 (Table 1). BSA with a $\mathrm{pI}$ of 5.3, has negative charge at neutral $\mathrm{pH}$, and it has been used to form biomimetically mineralized ZIF8 ${ }^{6}$. Fig. 1 showed the formation of ZIF particles using BSA, which agrees with the result in literature ${ }^{6,21,29}$.

Table 1. Different peptides/proteins for forming biomolecule@ZIF

\begin{tabular}{l|l|l}
\hline Protein/peptide & $\begin{array}{l}\text { Isoelectric } \\
\text { point }\end{array}$ & Amino acid sequence \\
\hline SurSi & 12.35 & MKQLAHSVSRLEHARKKRKK RKKRKKGGGY \\
Pexiganan & 11.7 & GIGKFLKKAKKFGKAFVKILKK \\
Lysozyme & 11.3 & \\
& 11.3 & MKKLADSLKKLARQVKKLESA \\
PS-Pexiganan-HH & 11.2 & PSGIGKFLKKAKKFGKAFVKILKKHH \\
AM1 & 8.08 & MKQLADSLHQLARQVSRLEHA-CONH 2 \\
Lac21 & 8.03 & MKQLADSLMQLARQVSRLESA-CONH ${ }_{2}$ \\
DAMP4 & 6.7 & MD(PSMKQLADS LHQLARQ VSRLEHAD) 4 \\
\hline BSA & 5.3 & \\
Lac21E & 3.95 & MEELADSLEELARQ VEELESA \\
M6A & 3.6 & DIESAQSDEEVE \\
\hline
\end{tabular}


Similarly, the biomineralization process of DAMP4, M6A and Lac21E under the same reaction conditions as of BSA was very quick (within seconds), as expected ${ }^{6,21,29}$. DAMP4, M6A and Lac21E contain mainly acidic amino acid residues, i.e. aspartate (D) and glutamate (E) (Table 1), which were deprotonated, hence, causing the biomolecules to exhibit global negative charges under the reaction $\mathrm{pH}$ 7.5. Such negatively charged biomolecules pose high affinity against the ZIF precursors due to the electrostatic attraction, which eventually induced the formation of ZIF particles. In contrast, the biomineralization process of cationic peptides having $\mathrm{pI}$ higher than the reaction $\mathrm{pH} 7.5$ (Table 1) was not instantaneous. Stirring of the reaction mixture was required to break the electrostatic repulsion barrier between the positively charged peptides and the ZIF precursors at $\mathrm{pH}$ 7.5. It took several hours for those peptides to induce the nucleation and growth of ZIF particles under stirring up to 500 revolutions per minute (rpm). The first indication of the particle formation was when the clear, transparent solution containing the reactants was transformed to a white, turbid solution after stirring for hours, whereas the control reaction (without the cationic peptides) did not.
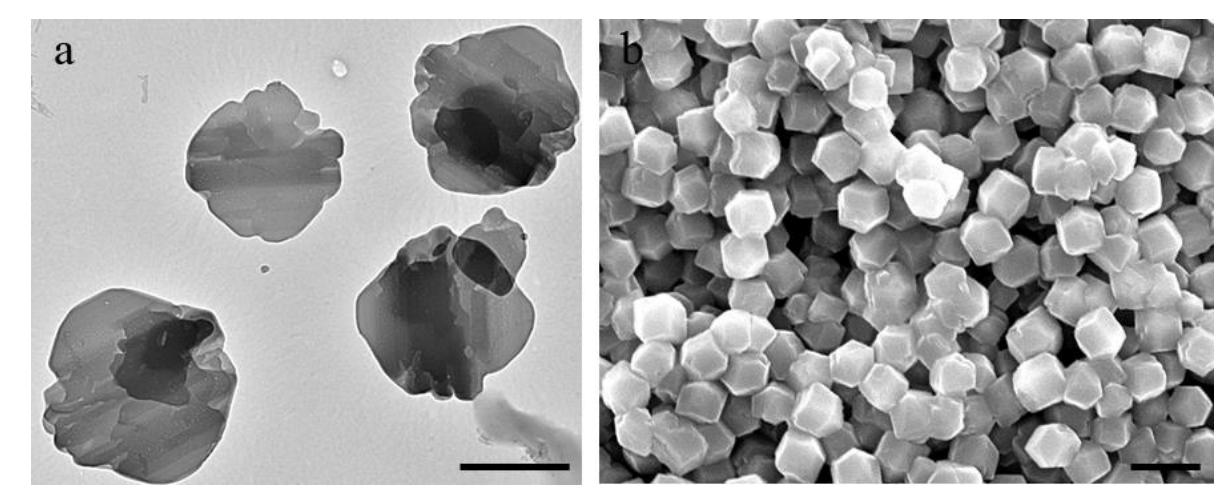

Fig. 1. Biomimetically mineralized ZIF particles using BSA. (a) TEM image of BSA@ZIF particles (Scale bar, $500 \mathrm{~nm}$ ). (b) SEM images of BSA@ZIF particles. Scale bar, $2 \mu \mathrm{m}$.

To systematically compare the speed of ZIF formation in the presence of different biomolecules, changes of the optical density of the solution containing the biomolecule, zinc acetate and 2-methylimidazole at $600 \mathrm{~nm}$ (OD600) was monitored over time. Fig. 2 showed the correlation between the time that takes for ZIF formation and the pI of different biomolecules. We can clearly observe the effect of the biomolecules' charge on ZIF formation. Again, for all the biomolecules with negative charges at $\mathrm{pH} \mathrm{7.5,} \mathrm{regardless} \mathrm{of} \mathrm{their} \mathrm{exact}$ charges, ZIF particles could be formed instantly. In contrast, it took much longer (about 3-5 hours) to form ZIF particles using those biomolecules with positive charges at $\mathrm{pH} 7.5$ at 500 rpm of stirring. In addition, there was no obvious relationship between the reaction rates and the pI when the pI was above 7.5 (Fig. 2). It was noted that the ZIF-formation reaction for PSpexiganan-HH@ZIFs was faster than that for pexiganan@ZIFs. These two peptides have the exact same sequence except that PS-pexiganan-HH contains additional proline-serine (PS) and two histidine $(\mathrm{HH})$ residues at the $\mathrm{N}$ - and $\mathrm{C}$-terminal of pexiganan, respectively. We hypothesized that the increased reaction rate of PS-pexiganan-HH under stirring was due to the presence of additional histidine residues which have high binding affinity against the ZIF metal 
precursor $\mathrm{Zn}^{2+}$ and thus promote the nucleation of the framework. The imidazole of histidine contains electron donor group which is known to readily form coordination bonds with metal ions including $\mathrm{Zn}^{2+32}$.

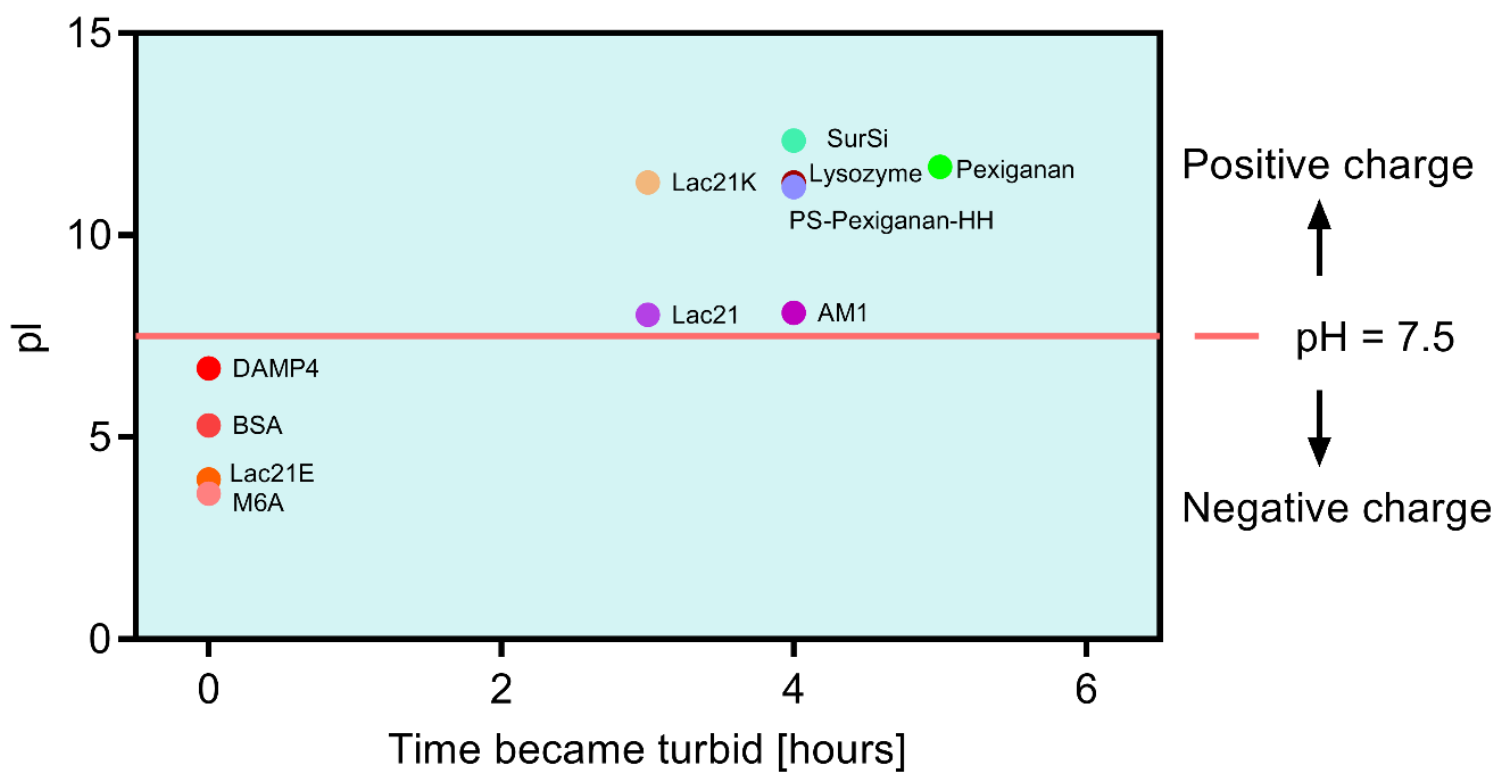

Fig. 2. Correlation between the biomolecules' isoelectric point ( $\mathrm{pI}$ ) and the reaction time to form biomolecule@ZIF particles. The pI of different peptides and proteins are plotted against the time when the solution of the reactants (i.e., a biomolecule, zinc acetate and 2methylimidazole in water) start becoming turbid under the stirring speed of $500 \mathrm{rpm}$ at room temperature.

Fig. 3 showed the TEM images of the peptides@ZIFs particles formed at $\mathrm{pH}$ 7.5. For those peptides@ZIFs forming with negatively charged peptides (low pI), the structure was more smooth and solid (Fig. 3g-i). But for positively charged peptides (high pI), the formed particles had flower-like flat-sheet crystals (Fig. 3a-f), and some of the sheet structure was very thin (Lac21K, Fig. 3e). To further investigate the formation of ZIF particles by using positively charged peptide, SurSi which has the highest charge at neutral $\mathrm{pH}$ was systematically studied. 

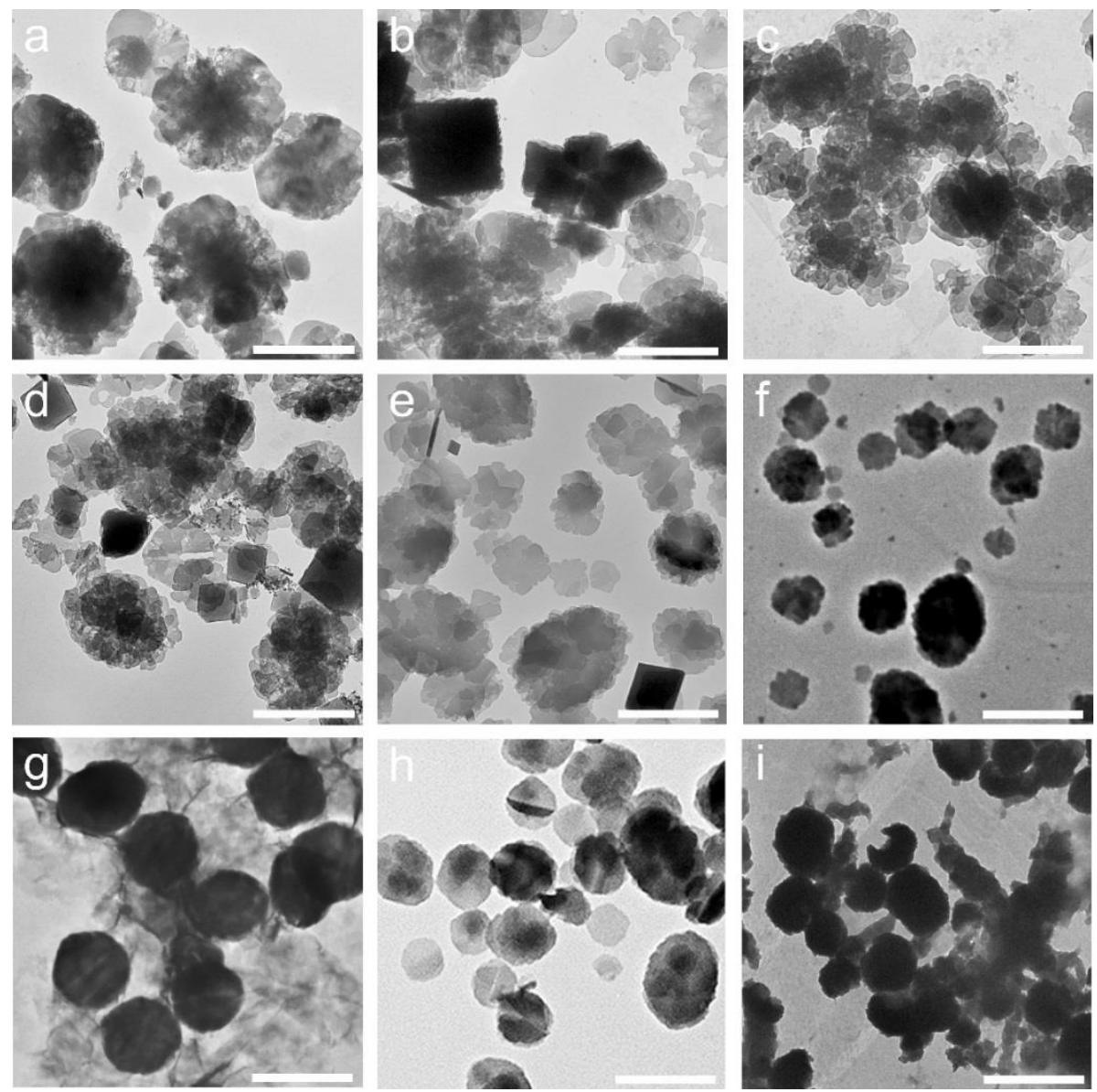

Fig. 3. TEM images of different peptides/proteins for biomimetic mineralization reactions. (a) SurSi, (b) Pexiganan, (c) PS-Pexiganan-HH, (d) Lac21, (e) Lac21K, (f) AM1, (g) Lac21E, (h) M6A, and (i) DAMP4. Scale bars, $1 \mu \mathrm{m}$.

SurSi, a designed peptide (Ac-MKQLAHSVSRLEH ARKKRKKRKKRKKGGGY-CONH 2 ), was used for the formation of biomolecules@ ZIFs. Firstly, the effect of stirring was investigated because stirring condition is vital in liquid phase reaction. In experiment, the solution remained clear for more than 24 hours without stirring while became turbid within 4 hours when the solution was stirred at $500 \mathrm{rpm}$ (Fig. 4). Besides, we found that stirring speed affected the reaction rate and that increasing the stirring speed accelerated the particle formation. OD600 was used to monitor the formation of SurSi@ZIF particles. Increasing the stirring speed led to the formation of more particles at the same reaction time as indicated by higher OD600. The TEM images in Fig. 4 (d-g) showed a variation of morphology with different stirring speeds. The images showed most of ZIFs particles exhibited flower-like flatsheet crystals. At a stirring speed of $100 \mathrm{rpm}$, many small crystals presented (Fig. 4d). When the stirring speed increased to $500 \mathrm{rpm}$, the number of small particles decreased leading to the formation of larger particles (Fig. 4 (e, f)). However, when the stirring speed was higher than $600 \mathrm{rpm}$, large aggregates were formed by appearance. The high dispersity (Đ) of ZIF particles associated with stirring was also observed by Cravillon et al which suggested to be due to the secondary nucleation caused by turbulence ${ }^{33}$. 
a

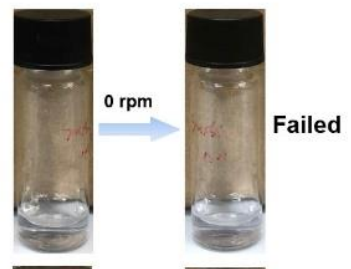

b
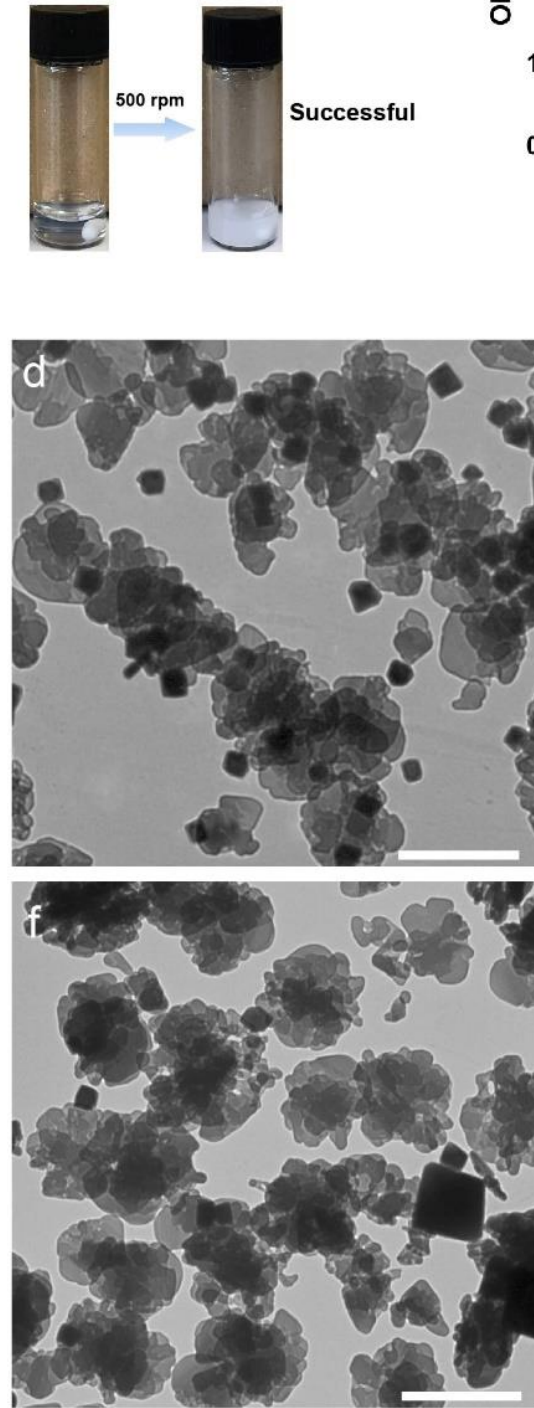
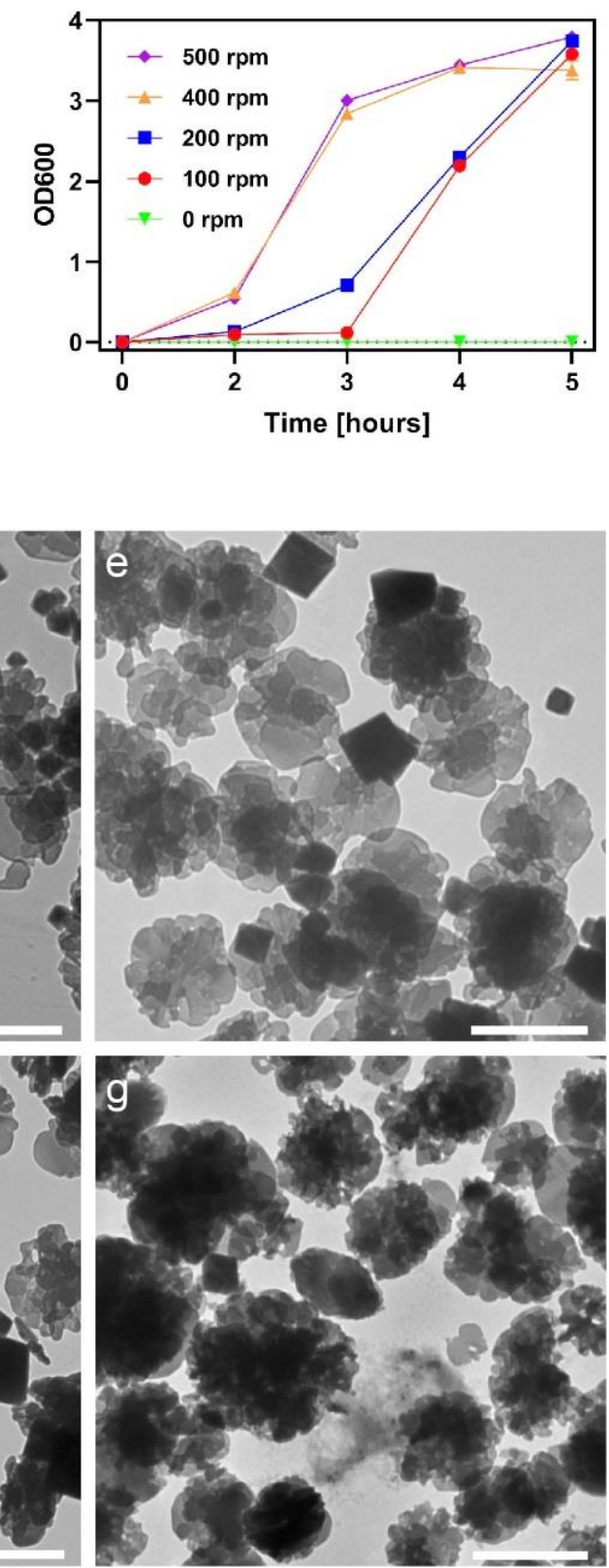

Fig. 4. Effect of stirring on SurSi@ZIFs formation. (a) Image showing no SurSi@ZIFs were synthesized after 12 hours under static condition. (b) Image showing SurSi@ZIFs were synthesized after 12 hours with a stirring speed of $500 \mathrm{rpm}$. (c) Effect of stirring speeds on SurSi@ZIFs formation. OD600 was used to monitor the formation of SurSi@ZIF particles. TEM images of SurSi@ZIFs with stirring speeds of (d) 100 rpm. (e) 200 rpm. (f) 400 rpm. (g) $500 \mathrm{rpm}$. Scale bars, $1 \mu \mathrm{m}$.

We further examined the effect of peptide concentration on SurSi@ZIF particles formation. Fig. 5 showed the increase of particle sizes with the SurSi concentration probably due to the aggregative growth mediated by SurSi-seeded clusters thus forming larger crystals ${ }^{34}$. Also, all the particles were negatively charged and had a flower-like flat sheet structure (Fig. 5 (h- 
j)). The thickness of the flat sheet also increased with the increasing SurSi concentration as measured by SEM, indicating that the growth of these flower-like structures was through a layer-by-layer stacking process, and we can observe some very thin structure as well.
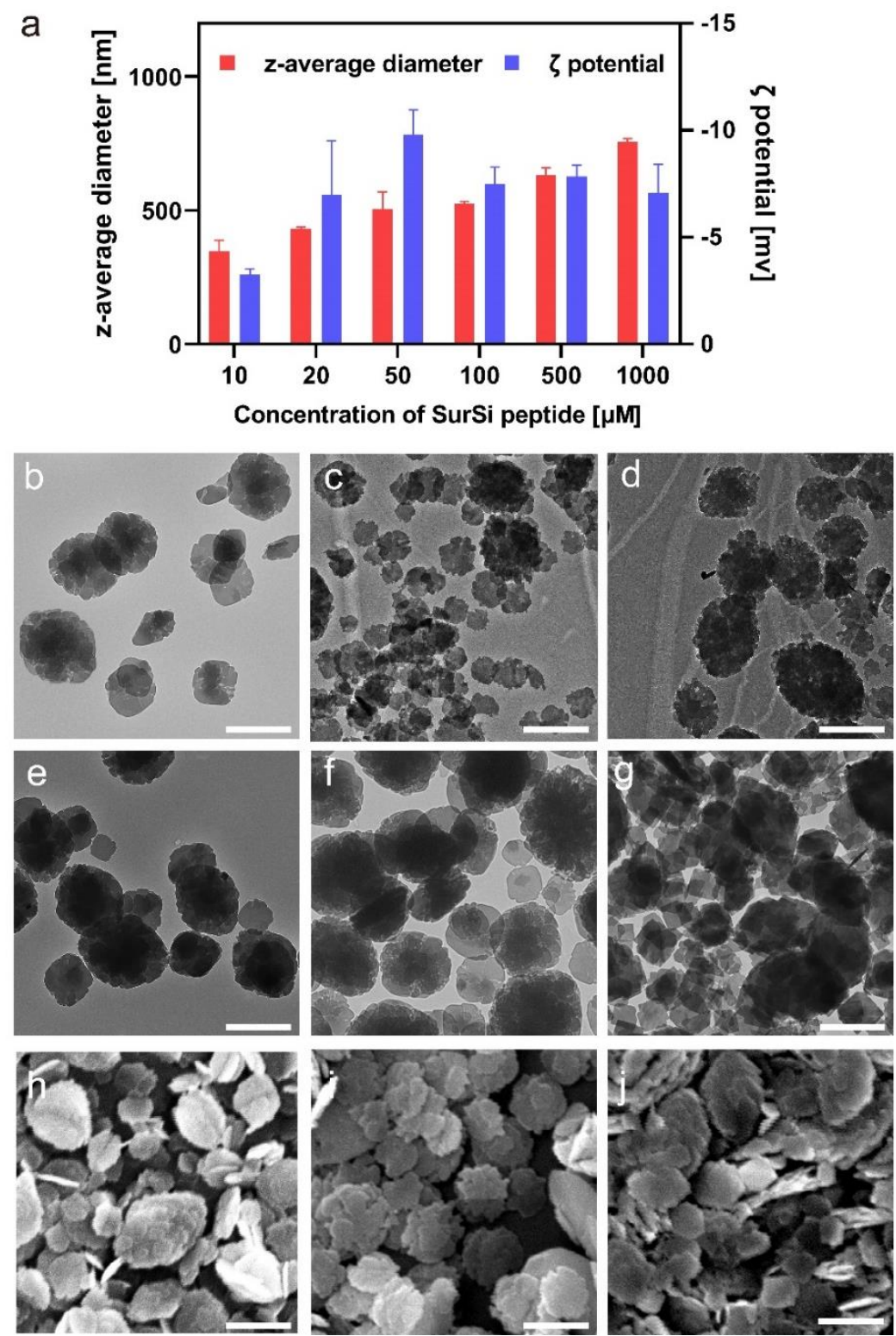

Fig. 5. SurSi@ZIF particles formed at different SurSi concentrations. (a) Average particle size and zeta potential of SurSi@ZIF. TEM images of SurSi@ZIF with a SurSi concentration of (b) $10 \mu \mathrm{M}$. (c) $20 \mu \mathrm{M}$ (d) $50 \mu \mathrm{M}$ (e) $100 \mu \mathrm{M}$ (f) $500 \mu \mathrm{M}$ (g) $1000 \mu \mathrm{M}$ and SEM images of SurSi@ZIF with SurSi concentration of (h) $10 \mu \mathrm{M}$ (i) $100 \mu \mathrm{M}$ (j) $1000 \mu \mathrm{M}$. Scale bars, $1 \mu \mathrm{m}$.

The XRD patterns of the SurSi@ZIFs were analyzed and compared to that of the BSA@ZIFs which are nearly identical (Fig. 6a) confirming the formation of the same ZIF structure. The FT-IR spectra (Fig. 6b) showed the absorption peaks at $1584 \mathrm{~cm}^{-1}(\mathrm{C}=\mathrm{N}$ stretching of imidazole) and $1400-1500 \mathrm{~cm}^{-1}$ (stretching of the imidazole ring), indicating the presence of ZIFs network ${ }^{35}$. It also shows the stretch characteristics of both SurSi peptide and BSA protein 
at around 1660 and $1510 \mathrm{~cm}^{-1}$, corresponding to amide $\mathrm{I}(\mathrm{C}=\mathrm{O}$ stretch $)$ and amide II $(\mathrm{C}-\mathrm{N}$ stretch and $\mathrm{N}-\mathrm{H}$ in-plane bend), respectively, suggesting the presence of SurSi peptides and BSA encapsulated within the ZIF particles.
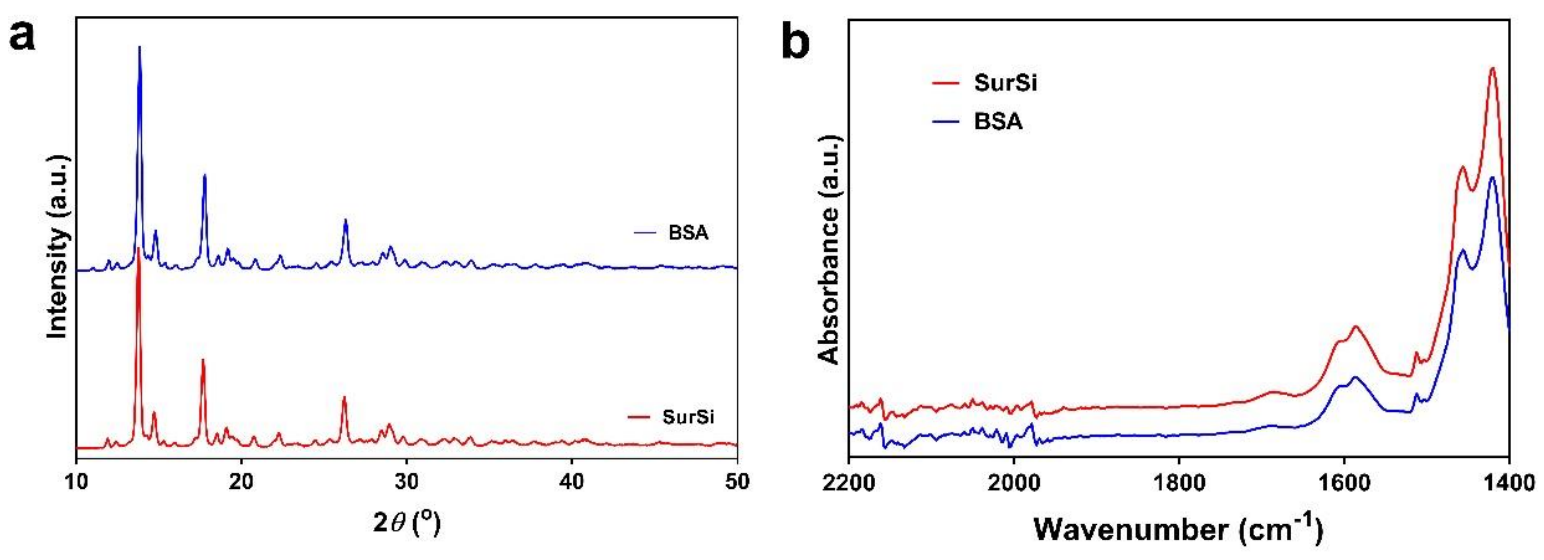

Fig. 6. Characterization of SurSi@ZIFs as compared to BSA@ZIFs. (a) XRD patterns. (b) FTIR patterns.

To further confirm that whether the peptides are encapsulated in the ZIF crystals, SurSi peptide was labeled with fluorescein isothiocyanate (FITC) and purified by dialysis. After biomimetic mineralization reaction and washing, CLSM was used for characterizing the products. The fluorescence images (Fig. 7 (a, b)) showed strong fluorescence of the ZIF crystals, indicating that SurSi peptides were encapsulated in the particles during the biomimetic nucleation and growth processes. TEM and SEM images (Fig. 7 (c, d)) showed the identical morphology of ZIF particles made by SurSi (Fig. 5) and FITC labeled SurSi suggesting that the presence of FITC did not affect the crystal formation. 


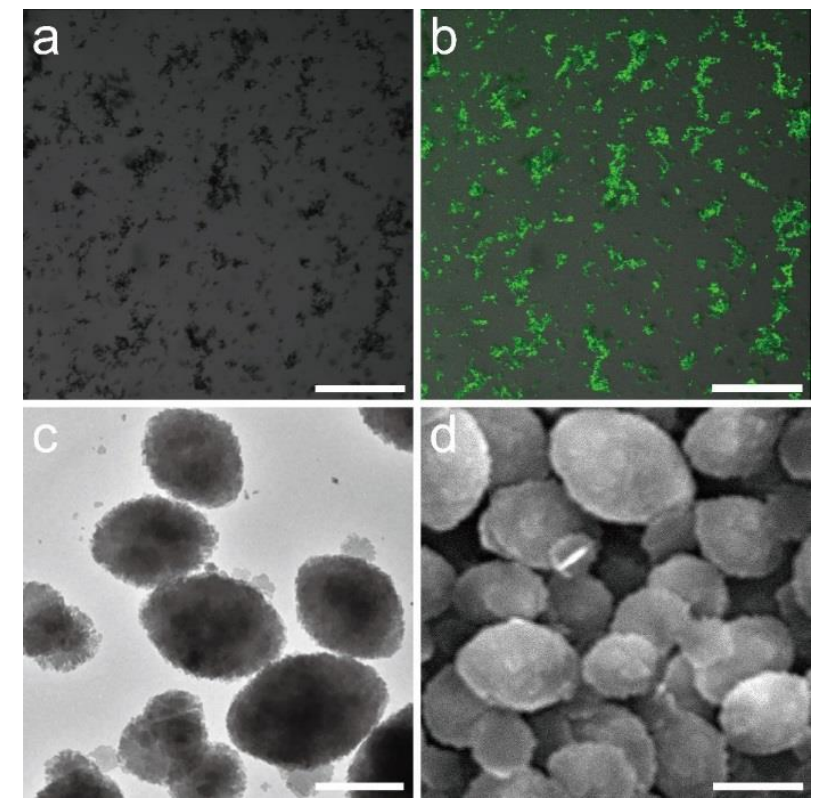

Fig. 7. ZIF particles crystallized around FITC labeled SurSi. (a) Confocal laser scanning micrographs bright field and (b) overlay image, as well as (c) TEM image and (d) SEM image. Scale bars of (a) and (b), $100 \mu \mathrm{m}$, and (c) and (d), $1 \mu \mathrm{m}$.

\section{Conclusion}

In this study we systematically investigated the effect of biomolecule charge on ZIF formation. Our results showed that for biomolecules with negative charge or low pI, the biomimetic mineralization occurred immediately. In contrast, for the peptides with high pIs, the reaction did not happen within 24 hours under static conditions. Stirring is essential to make peptide@ZIFs using peptides with high pIs, and the particles could form within 5 hours. XRD, FT-IR and confocal laser scanning microscopy confirmed the encapsulation of the peptides within the ZIFs. It is also noted that the stirring speed and type of peptides also affect the size and morphology of peptide@ZIFs. For SurSi, a designed peptide which could form a 2dimensional flower-like crystal, it was found that higher stirring speed led to larger and more homogeneous particles. SurSi@ZIFs particles became larger with higher concentration of SurSi peptide. Furthermore, we studied the effect of peptide concentration on the formation of ZIF-8 particles and found that SurSi@ZIFs particles became larger with the increase of SurSi peptide concentration. Overall, our results demonstrate that peptide having low pIs could exhibit quick binding to ZIFs, while peptides with high pIs could only form ZIFs with stirring.

\section{Conflicts of interest}

There are no conflicts to declare.

\section{Acknowledgements}

This work was supported by the Australian Research Council (DP150100798, LP140100424, FT140100726). This work was performed in part at the Queensland node of the Australian National Fabrication Facility, a company established under the National Collaborative Research Infrastructure Strategy to provide nano and microfabrication facilities for Australia's 
researchers. The authors acknowledge the facilities, and the scientific and technical assistance, of the Australian Microscopy \& Microanalysis Research Facility at the Centre for Microscopy and Microanalysis, The University of Queensland.

\section{References}

1. H. Furukawa, K. E. Cordova, M. O'Keeffe and O. M. Yaghi, Science, 2013, 341, 974-+.

2. M. X. Wu and Y. W. Yang, Adv. Mater., 2017, 29.

3. D. Yang and B. C. Gates, Acs Catal., 2019, 9, 1779-1798.

4. M. Hasan, S. Latifi, C. Kahn, A. Tamayol, R. Habibey, E. Passeri, M. Linder and E. ArabTehrany, Mar. Drugs, 2018, 16, 218.

5. L. E. Kreno, K. Leong, O. K. Farha, M. Allendorf, R. P. Van Duyne and J. T. Hupp, Chem. Rev., 2012, 112, 1105-1125.

6. K. Liang, R. Ricco, C. M. Doherty, M. J. Styles, S. Bell, N. Kirby, S. Mudie, D. Haylock, A. J. Hill, C. J. Doonan and P. Falcaro, Nat. Commun., 2015, 6.

7. K. Liang, C. J. Coghlan, S. G. Bell, C. Doonan and P. Falcaro, Chem. Commun., 2016, 52, 473476.

8. X. Z. Lian, Y. Fang, E. Joseph, Q. Wang, J. L. Li, S. Banerjee, C. Lollar, X. Wang and H. C. Zhou, Chem. Soc. Rev., 2017, 46, 3386-3401.

9. E. Gkaniatsou, C. Sicard, R. Ricoux, J. P. Mahy, N. Steunou and C. Serre, Mater Horiz, 2017, 4, 55-63.

10. J. B. Bailey, L. Zhang, J. A. Chiong, S. Ahn and F. A. Tezcan, J Am Chem Soc, 2017, 139, 8160-8166.

11. G. Fan, C. M. Dundas, C. Zhang, N. A. Lynd and B. K. Keitz, ACS Appl. Mater. Interfaces, 2018, 10, 18601-18609.

12. K. Liang, J. J. Richardson, J. W. Cui, F. Caruso, C. J. Doonan and P. Falcaro, Adv. Mater., 2016, 28, 7910-7914.

13. T. Ye, Y. F. Liu, M. Luo, X. Xiang, X. H. Ji, G. H. Zhou and Z. K. He, Analyst, 2014, 139, 1721-1725.

14. M. Giardiello, N. J. Liptrott, T. O. McDonald, D. Moss, M. Siccardi, P. Martin, D. Smith, R. Gurjar, S. P. Rannard and A. Owen, Nat. Commun., 2016, 7, 13184.

15. X. L. Wu, J. Ge, C. Yang, M. Hou and Z. Liu, Chem. Commun., 2015, 51, 13408-13411.

16. G. Cheng, W. Q. Li, L. Ha, X. H. Han, S. J. Hao, Y. Wan, Z. G. Wang, F. P. Dong, X. Zou, Y. W. Mao and S. Y. Zheng, J Am Chem Soc, 2018, 140, 7282-7291.

17. B. L. Chen, Z. X. Yang, Y. Q. Zhu and Y. D. Xia, J Mater Chem A, 2014, 2, 16811-16831.

18. J. P. Zhang, Y. B. Zhang, J. B. Lin and X. M. Chen, Chem. Rev., 2012, 112, 1001-1033.

19. K. Kida, M. Okita, K. Fujita, S. Tanaka and Y. Miyake, Crystengcomm, 2013, 15, 1794-1801.

20. Y. C. Pan, Y. Y. Liu, G. F. Zeng, L. Zhao and Z. P. Lai, Chem. Commun., 2011, 47, 2071-2073.

21. W. B. Liang, R. Ricco, N. K. Maddigan, R. P. Dickinson, H. S. Xu, Q. W. Li, C. J. Sumby, S. G. Bell, P. Falcaro and C. J. Doonan, Chem. Mater., 2018, 30, 1069-1077.

22. D. Wibowo, C. X. Zhao and A. P. J. Middelberg, Chem. Commun., 2014, 50, 11325-11328.

23. A. F. Dexter, A. S. Malcolm and A. P. J. Middelberg, Nat Mater, 2006, 5, 502-506. 
24. R. Fairman, H. G. Chao, L. Mueller, T. B. Lavoie, L. Shen, J. Novotny and G. R. Matsueda, Protein Sci., 1995, 4, 1457-1469.

25. A. P. Middelberg and M. Dimitrijev-Dwyer, ChemPhysChem, 2011, 12, 1426-1429.

26. C. X. Zhao, M. D. Dwyer, A. L. Yu, Y. Wu, S. Fang and A. P. Middelberg, Biotechnol. Bioeng., 2015, 112, 957-964.

27. B. Sun, D. Wibowo, A. P. Middelberg and C.-X. Zhao, AMB Express, 2018, 8, 6.

28. M. D. Dwyer, M. Brech, L. Yu and A. P. Middelberg, Chem. Eng. Sci., 2014, 105, 12-21.

29. N. K. Maddigan, A. Tarzia, D. M. Huang, C. J. Sumby, S. G. Bell, P. Falcaro and C. J. Doonan, Chem. Sci., 2018, 9, 4217-4223.

30. J. He, S. S. Sun, M. Z. Lu, Q. P. Yuan, Y. H. Liu and H. Liang, Chem. Commun., 2019, 55, 6293-6296.

31. K. Liang, R. Ricco, C. M. Doherty, M. J. Styles and P. Falcaro, Crystengcomm, 2016, 18, 42644267.

32. L. Zhou, S. Li, Y. Su, X. Yi, A. Zheng and F. Deng, J. Phys. Chem. B, 2013, 117, 8954-8965.

33. J. Cravillon, R. Nayuk, S. Springer, A. Feldhoff, K. Huber and M. Wiebcke, Chem. Mater., 2011, 23, 2130-2141.

34. T. T. Chen, J. T. Yi, Y. Y. Zhao and X. Chu, J Am Chem Soc, 2018, 140, 9912-9920.

35. C. Z. Wang, H. C. Sun, J. Y. Luan, Q. S. Jiang, S. Tadepalli, J. J. Morrissey, E. D. Kharasch and S. Singamaneni, Chem. Mater., 2018, 30, 1291-1300. 